\title{
Electronic and optical properties of $\mathrm{Cu}_{2} \mathrm{XSnS}_{4}(\mathrm{X}=\mathrm{Be}, \mathrm{Mg}, \mathrm{Ca}, \mathrm{Mn}, \mathrm{Fe}$, and $\mathrm{Ni})$ and the impact of native defect pairs
}

Rongzhen Chen, and Clas Persson

Citation: Journal of Applied Physics 121, 203104 (2017); doi: 10.1063/1.4984115

View online: https://doi.org/10.1063/1.4984115

View Table of Contents: http://aip.scitation.org/toc/jap/121/20

Published by the American Institute of Physics

\section{Articles you may be interested in}

Hierarchical structures of magnetic nanoparticles for controlling magnetic interactions on three different length scales

Journal of Applied Physics 121, 224303 (2017); 10.1063/1.4983849

Noncollinear antiferromagnetic Haldane magnon insulator

Journal of Applied Physics 121, 223904 (2017); 10.1063/1.4985615

Electronic and optical properties of $\mathrm{Cu}_{2} \mathrm{ZnSnS}_{4}$ and $\mathrm{Cu}_{2} \mathrm{ZnSnSe}_{4}$ Journal of Applied Physics 107, 053710 (2010); 10.1063/1.3318468

Optical properties of bimodally distributed InAs quantum dots grown on digital $\mathrm{AlAs}_{0.56} \mathrm{Sb}_{0.44}$ matrix for use in intermediate band solar cells

Journal of Applied Physics 121, 214304 (2017); 10.1063/1.4984832

Determining interface properties limiting open-circuit voltage in heterojunction solar cells

Journal of Applied Physics 121, 185301 (2017); 10.1063/1.4982752

Band offsets of $\mathrm{Ag}_{2} \mathrm{ZnSnSe} 4 / \mathrm{CdS}$ heterojunction: An experimental and first-principles study

Journal of Applied Physics 121, 215305 (2017); 10.1063/1.4984315

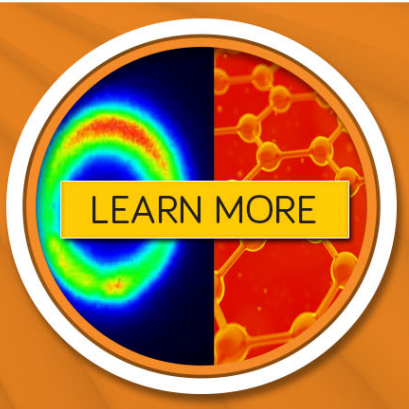




\title{
Electronic and optical properties of $\mathrm{Cu}_{2} X \mathrm{SnS}_{4}(X=\mathrm{Be}, \mathrm{Mg}, \mathrm{Ca}, \mathrm{Mn}, \mathrm{Fe}$, and $\mathrm{Ni)}$ and the impact of native defect pairs
}

\author{
Rongzhen Chen ${ }^{1,2, a)}$ and Clas Persson ${ }^{1,2,3}$ \\ ${ }^{1}$ Department of Materials Science and Engineering, KTH Royal Institute of Technology, SE-100 44 Stockholm, \\ Sweden \\ ${ }^{2}$ Centre for Materials Science and Nanotechnology, University of Oslo, P.O. Box 1048 Blindern, \\ NO-0316 Oslo, Norway \\ ${ }^{3}$ Department of Physics, University of Oslo, P.O. Box 1048 Blindern, NO-0316 Oslo, Norway
}

(Received 8 February 2017; accepted 12 May 2017; published online 31 May 2017)

\begin{abstract}
Reducing or controlling cation disorder in $\mathrm{Cu}_{2} \mathrm{ZnSnS}_{4}$ is a major challenge, mainly due to low formation energies of the anti-site pair $\left(\mathrm{Cu}_{\mathrm{Zn}}^{-}+\mathrm{Zn}_{\mathrm{Cu}}^{+}\right)$and the compensated $\mathrm{Cu}$ vacancy $\left(\mathrm{V}_{\mathrm{Cu}}^{-}+\mathrm{Zn}_{\mathrm{Cu}}^{+}\right)$. We study the electronic and optical properties of $\mathrm{Cu}_{2} X \mathrm{SnS}_{4}(\mathrm{CXTS}$, with $X=\mathrm{Be}, \mathrm{Mg}$, $\mathrm{Ca}, \mathrm{Mn}, \mathrm{Fe}$, and $\mathrm{Ni}$ ) and the impact of defect pairs, by employing the first-principles method within the density functional theory. The calculations indicate that these compounds can be grown in either the kesterite or stannite tetragonal phase, except $\mathrm{Cu}_{2} \mathrm{CaSnS}_{4}$ which seems to be unstable also in its trigonal phase. In the tetragonal phase, all six compounds have rather similar electronic band structures, suitable band-gap energies $E_{\mathrm{g}}$ for photovoltaic applications, as well as good absorption coefficients $\alpha(\omega)$. However, the formation of the defect pairs $\left(\mathrm{Cu}_{X}+X_{\mathrm{Cu}}\right)$ and $\left(\mathrm{V}_{\mathrm{Cu}}+X_{\mathrm{Cu}}\right)$ is an issue for these compounds, especially considering the anti-site pair which has formation energy in the order of $\sim 0.3 \mathrm{eV}$. The $\left(\mathrm{Cu}_{X}+X_{\mathrm{Cu}}\right)$ pair narrows the energy gap by typically $\Delta E_{\mathrm{g}} \approx 0.1-0.3 \mathrm{eV}$, but for $\mathrm{Cu}_{2} \mathrm{NiSnS}_{4}$, the complex yields localized in-gap states. Due to the low formation energy of $\left(\mathrm{Cu}_{X}+X_{\mathrm{Cu}}\right)$, we conclude that it is difficult to avoid disordering from the high concentration of antisite pairs. The defect concentration in $\mathrm{Cu}_{2} \mathrm{BeSnS}_{4}$ is however expected to be significantly lower (as much as $\sim 10^{4}$ times at typical device operating temperature) compared to the other compounds, which is partly explained by larger relaxation effects in $\mathrm{Cu}_{2} \mathrm{BeSnS}_{4}$ as the two anti-site atoms have different sizes. The disadvantage is that the stronger relaxation has a stronger impact on the bandgap narrowing. Therefore, instead of trying to reduce the anti-site pairs, we suggest that one shall try to compensate $\left(\mathrm{Cu}_{X}+X_{\mathrm{Cu}}\right)$ with $\left(\mathrm{V}_{\mathrm{Cu}}+X_{\mathrm{Cu}}\right)$ or other defects in order to stabilize the gap energy. Published by AIP Publishing. [http://dx.doi.org/10.1063/1.4984115]
\end{abstract}

\section{INTRODUCTION}

Chalcopyrite materials are an attractive group of materials for thin film photovoltaics (PV). $\mathrm{Cu}_{2} \mathrm{ZnSn}(\mathrm{S}, \mathrm{Se})_{4}$ (CZTSSe) is considered as a promising absorber material, and the best research cell efficiency today is $\sim 12.6 \%$ achieved in the lab condition. ${ }^{1}$ There are extensive investigations and developments of CZTSSe world-wide, and many of these studies focus on understanding the defects in the material. ${ }^{2-9}$ Researchers also started to explore similar compounds but substituting $\mathrm{Zn}$ by transition metal atoms, such as $\mathrm{Mn}, \mathrm{Fe}, \mathrm{Co}$, and Ni. For instance, the fundamental band-gap energy $E_{\mathrm{g}}$ of $\mathrm{Cu}_{2} \mathrm{MnSnS}_{4}$ is experimentally estimated to be between 1.18 and $1.63 \mathrm{eV}$ depending on the heat treatment, ${ }^{10}$ and a solar cell based on $\mathrm{Cu}_{2} \mathrm{MnSnS}_{4}$ has an efficiency of $0.49 \%$. The band-gap energies of synthesized $\mathrm{Cu}_{2} \mathrm{FeSnS}_{4}$ nanocrystals and $\mathrm{Cu}_{2} \mathrm{CoSnS}_{4}$ and $\mathrm{Cu}_{2} \mathrm{NiSnS}_{4}$ nanoparticles are $\sim 1.33$ or $\sim 1.5 \mathrm{eV}, 11,12$ $\sim 1.40^{13}$ and $\sim 1.40 \mathrm{eV},{ }^{14,15}$ respectively. Moreover, kesterite $\mathrm{Cu}_{2} \mathrm{MgSnS}_{4}$ nanoparticles without a secondary phase have been synthesized using a hot-injection method. ${ }^{16}$ From firstprinciples calculations with the generalized gradient approximation (GGA), Wang et al. ${ }^{17}$ have found that kesterite

\footnotetext{
a) Author to whom correspondence should be addressed: Rongzhen.Chen@ mse.kth.se
}

$\mathrm{Cu}_{2} \mathrm{CdSnS}_{4}$ and $\mathrm{Cu}_{2} \mathrm{HgSnS}_{4}$ are thermodynamically stable, but kesterite $\mathrm{Cu}_{2} \mathrm{MgSnS}_{4}$ and especially kesterite $\mathrm{Cu}_{2} \mathrm{CaSnS}_{4}$ are not stable. Complementarily, Zhong et al. ${ }^{18}$ found, using a hybrid functional, that stannite $\mathrm{Cu}_{2} \mathrm{MgSnS}_{4}$ (and $\mathrm{Cu}_{2} \mathrm{MgSnSe}_{4}$ ) is thermodynamically stable, but, similar to Wang et al., that kesterite and stannite phases of $\mathrm{Cu}_{2} \mathrm{CaSnS}_{4}$ (and $\mathrm{Cu}_{2} \mathrm{CaSnSe}_{4}$ ) are unstable with respect to competing compounds.

Some of the above-mentioned compounds can be alternative candidates as thin film PV materials; however, better knowledge of the synthesis processes as well as a deeper understanding of the impact of native defects is needed. That is, in $\mathrm{Cu}_{2} \mathrm{ZnSnS}_{4}$ (CZTS), copper vacancy $\mathrm{V}_{\mathrm{Cu}}^{-}$is an important shallow acceptor, and the anti-site defects involve shallow donors $\mathrm{Zn}_{\mathrm{Cu}}^{+}$and shallow acceptors $\mathrm{Cu}_{\mathrm{Zn}}^{-} \cdot{ }^{5,19} \mathrm{It}$ is known that $\mathrm{Cu}-\mathrm{Zn}$ disorder induces band-gap energy fluctuations in the material. ${ }^{4}$ Therefore, it is important to investigate how to reduce the concentration of the anti-site pair (ASP) in CZTSSe. Yuan et al. ${ }^{20}$ suggested that $\mathrm{Zn}$ shall be substituted by the large-size atom $\mathrm{Cd}$ and alternative $\mathrm{Cu}$ substituted by $\mathrm{Ag}$, to suppress the formation of anti-site defects. They found that while $\mathrm{Cd}_{\mathrm{Cu}}^{+}$in $\mathrm{Cu}_{2} \mathrm{CdSnS}_{4}$ had as low formation energy as $\mathrm{Zn}_{\mathrm{Cu}}^{+}$in CZTS, the corresponding anti-site $\mathrm{Zn}_{\mathrm{Ag}}^{+}$ in $\mathrm{Ag}_{2} \mathrm{ZnSnS}_{4}$ had significantly much higher formation energy. Therefore, further investigations of CXTSSe (i.e., where $\mathrm{Zn}$ is replaced by the element $X$ ) are expected to 
reveal a fundamental understanding of the defect physics in these quaternary chalcopyrites.

In this work, the electronic and optical properties as well as the formation of native ASP defects $\left(\mathrm{Cu}_{X}+X_{\mathrm{Cu}}\right)$ and $\left(\mathrm{V}_{\mathrm{Cu}}+X_{\mathrm{Cu}}\right)$ are theoretically explored for tetragonal $\mathrm{Cu}_{2} X \mathrm{SnS}_{4}$ (CXTS, with $X=\mathrm{Be}, \mathrm{Mg}, \mathrm{Ca}, \mathrm{Mn}, \mathrm{Fe}$, and $\mathrm{Ni}$ ) within the framework of the density functional theory (DFT). We consider the transition metal atoms $\mathrm{Mn}, \mathrm{Fe}$, and $\mathrm{Ni}$ to study the magnetic effects, and we include Be to analyze if local relaxation for a small-size atom suppresses the disorder due to ASPs. $\mathrm{Mg}$ is interesting as $\mathrm{Cu}_{2} \mathrm{MgSnS}_{4}$ is experimentally prepared and investigated. $\mathrm{Ca}$ is included in order to study trends in the band-gap energies $E_{\mathrm{g}}$, the optical properties, and the defect formation energies for compounds with group-IIA elements. For the considered quaternary chalcopyrites, there are to our knowledge no earlier defect studies on $\mathrm{Cu}_{2} \mathrm{BeSnS}_{4}, \mathrm{Cu}_{2} \mathrm{MnSnS}_{4}, \mathrm{Cu}_{2} \mathrm{FeSnS}_{4}$, and $\mathrm{Cu}_{2} \mathrm{NiSnS}_{4}$ and only a few defect studies on the other compounds.

We find that for tetragonal $\mathrm{Cu}_{2} \mathrm{MgSnS}_{4}, \mathrm{Cu}_{2} \mathrm{CaSnS}_{4}$, $\mathrm{Cu}_{2} \mathrm{FeSnS}_{4}$, and $\mathrm{Cu}_{2} \mathrm{MnSnS}_{4}$, the stannite (ST) phase is more stable (or at least less unstable) compared to the kesterite (KS) phase, while the opposite is true for $\mathrm{Cu}_{2} \mathrm{BeSnS}_{4}$ and $\mathrm{Cu}_{2} \mathrm{NiSnS}_{4}$. For $\mathrm{Cu}_{2} \mathrm{CaSnS}_{4}$, the formation energy of the trigonal phase is lower than that of the ST phase, but even the trigonal phase of $\mathrm{Cu}_{2} \mathrm{CaSnS}_{4}$ is not stable with respect to chemical decomposing compounds. The absorption coefficients of CXTS are calculated with a dense k-mesh, ${ }^{21}$ and we find that overall the coefficients are similar to those of CZTS apart from having slightly different onset energies. Remarkably, the absorption coefficient of $\mathrm{Cu}_{2} \mathrm{NiSnS}_{4}$ is much higher in a broad energy range than those of the other compounds, and this compound has a band-gap energy close to the optimum value $(\sim 1.3 \mathrm{eV})$ for maximum device efficiency in the ShockleyQueisser (SQ) limit. ${ }^{22,23}$ From the defect analysis, however, we find that $\mathrm{Cu}_{2} \mathrm{FeSnS}_{4}$ and $\mathrm{Cu}_{2} \mathrm{NiSnS}_{4}$ may not be suitable PV absorber materials as their point defect or ASP forms localized in-gap states. $\mathrm{Cu}_{2} \mathrm{MgSnS}_{4}$ and $\mathrm{Cu}_{2} \mathrm{MnSnS}_{4}$ have similar (but somewhat smaller) absorption coefficients and similar ASP formation energies compared to CZTS. From that perspective, substituting $\mathrm{Zn}$ by $X=\mathrm{Mg}$ or $\mathrm{Mn}$ is not expected to improve the PV properties. $\mathrm{Cu}_{2} \mathrm{BeSnS}_{4}$, on the other hand, has a higher absorption coefficient between $E_{\mathrm{g}}+0.6 \mathrm{eV}$ and $E_{\mathrm{g}}+1.2 \mathrm{eV}$ than CZTS for its corresponding energy region. Moreover, partly due to stronger relaxation effects, $\mathrm{Cu}_{2} \mathrm{BeSnS}_{4}$ also has higher defect formation energy of its ASP, implying that the ASP concentration in $\mathrm{Cu}_{2} \mathrm{BeSnS}_{4}$ is significantly lower than in the other CXTS compounds. The disadvantage of $\mathrm{Be}$ is of course handling of the element and its toxicity.

\section{COMPUTATIONAL DETAILS}

The calculations are performed by means of the plane augmented wave formalism within the DFT as implemented in the VASP program package. ${ }^{24,25}$ CXTS typically crystallize in the KS phase (space group $S_{4}^{2}$; no. 82 ) or in the ST phase (space group $D_{2 d}^{11}$; no. 121). We determine the ground state phase from the total energy, via a fully relaxed process. For $\mathrm{Cu}_{2} \mathrm{MnSnS}_{4}, \mathrm{Cu}_{2} \mathrm{FeSnS}_{4}$, and $\mathrm{Cu}_{2} \mathrm{NiSnS}_{4}$ with magnetic transition metal atoms, we consider the ferromagnetic and three antiferromagnetic (AFM) configurations (in both the KS and ST phases). For $\mathrm{Cu}_{2} \mathrm{CaSnS}_{4}$, we compare some results with the trigonal phase (space group $C_{3}^{2}$; no. 144). $\mathrm{Cu}_{2} X \mathrm{SnS}_{4}$ $(X=\mathrm{Be}, \mathrm{Mg}$, and $\mathrm{Ca})$ and CZTS are relaxed using the Perdew-Burke-Ernzerhof ${ }^{26}$ GGA exchange-correlation functional revised for solids (PBEsol). ${ }^{27} \mathrm{Cu}_{2} X \mathrm{SnS}_{4}(X=\mathrm{Mn}, \mathrm{Fe}$, and $\mathrm{Ni}$ ) are relaxed with PBEsol with an onsite Coulomb interaction correction ${ }^{28}$ of the $d$-like orbitals for the transition metal atoms (i.e., PBEsol $+\mathrm{U}$ ) since it has been demonstrated that this correction is crucial to accurately determine the magnetic configuration and lattice parameters for magnetic materials using local potential, ${ }^{29}$ which also our test calculation confirms. Here, we choose $U_{\mathrm{d}}(\mathrm{Mn})=4.0 \mathrm{eV}, U_{\mathrm{d}}(\mathrm{Fe})=4.6 \mathrm{eV}$, $U_{\mathrm{d}}(\mathrm{Ni})=5.1 \mathrm{eV}$, and $U_{\mathrm{d}}(\mathrm{Cu})=4 \mathrm{eV}$, according to Setyawan et $a l .{ }^{30}$ With the corrected potential on the $d$-like orbitals, the $d$-like energy states are corrected and the band gap is also opened moderately (by $\sim 0.3 \mathrm{eV}$ ), which is a normal effect in semiconductors with strong $d$-like states in the valence bands. ${ }^{31}$ The crystalline structures are fully relaxed until the total energy and the residual force on each atom show convergence within 0.1 and $10 \mathrm{meV} / \AA$, respectively. From the relaxed structures, the total energies of the structure (both defect-free and crystals with defects) are determined from the Heyd-Scuseria-Ernzerhof functional with the standard parameters for mixing and screening (i.e., HSE06). ${ }^{32}$

The electronic and optical properties of the defect-free compounds are modeled using 16 atom unit cells. For the defect calculations, we use relatively small unit cells of 64 atoms, which simulate neutral native defects at high concentrations in order to see how disorder changes the band-gap energy. The use of small cells is also justified by the fact that we focus the study on neutral defects, and we do not calculate transition energies. The band structure and density-of-states (DOS) are computed with the HSE06 potential, and we estimate that the error bar of predicted fundamental band-gap energies is $0.1-0.2 \mathrm{eV}$, which is a typical error bar for the HSE06. The DOS is calculated for the large-cell structures with defects using $\mathrm{K}=2 \times 2 \times 2 \Gamma$-centered Monkhorst-Pack like k-meshes. The optical properties, however, require a much larger $\mathbf{k}$-mesh for describing details in the dispersion of the optical transitions, ${ }^{21}$ especially for photon energies near the band-gap energy. Therefore, the absorption coefficients $\alpha(\omega)$ of $\mathrm{Cu}_{2} X \mathrm{SnS}_{4}$ are modeled with $\mathrm{K}=16 \times 24 \times 24 \Gamma$-centered $\mathbf{k}$-meshes, which implies 4612 k-points in the irreducible Brillouin zone (IBZ). The absorption coefficients are determined directly from the complex dielectric function, using the modified tetrahedron integration method with a $0.01 \mathrm{eV}$ smearing in the KramersKronig transformation relation. For computational reasons, we use PBEsol for $X=\mathrm{Be}, \mathrm{Mg}$, and $\mathrm{Ca}$ and $\mathrm{PBEsol}+\mathrm{U}$ for $X=\mathrm{Mn}, \mathrm{Fe}$, and Ni. Overall, the results obtained by using these potentials and a smaller k-mesh agree fairly well with the corresponding spectra obtained from HSE06 calculations.

\section{RESULTS}

\section{A. Crystalline phases, electronic structures, and optical properties}

The CXTS compounds are analyzed for the tetragonal KS or ST structures. For $\mathrm{Cu}_{2} \mathrm{MnSnS}_{4}, \mathrm{Cu}_{2} \mathrm{FeSnS}_{4}$, and 
$\mathrm{Cu}_{2} \mathrm{NiSnS}_{4}$, we consider four magnetic phases (one ferromagnetic and three antiferromagnetic configurations), and the most stable magnetic configuration is the antiferromagnetic phase described by the yellow arrows in Fig. 1. The most stable configurations for ST and KS are henceforth denoted as ST-AFM and KS-AFM. From the total energy $E_{\text {tot }}$, we find that the most stable structures are KS, ST, ST, ST-AFM, ST$\mathrm{AFM}$, and KS-AFM for CXTS with $X=\mathrm{Be}, \mathrm{Mg}, \mathrm{Ca}, \mathrm{Mn}, \mathrm{Fe}$, and $\mathrm{Ni}$, respectively. CZTS is known to have KS as its most stable phase. The total energy differences between the KS and ST phases are 198, 37, 479, and $50 \mathrm{meV} /$ cell (16 atom cell) for $\mathrm{Cu}_{2} \mathrm{BeSnS}_{4}, \mathrm{Cu}_{2} \mathrm{MgSnS}_{4}, \mathrm{Cu}_{2} \mathrm{CaSnS}_{4}$, and $\mathrm{Cu}_{2} \mathrm{ZnSnS}_{4}$, respectively. Specifically for $\mathrm{Cu}_{2} \mathrm{MgSnS}_{4}$ (and also for $\mathrm{Cu}_{2} \mathrm{ZnSnS}_{4}$ ), the presence of secondary phases in the materials is most likely possible. For $\mathrm{Cu}_{2} \mathrm{MnSnS}_{4}$, the total energy differences between the most stable phase (ST-AFM) and other phases are between 4 and $59 \mathrm{meV} / \mathrm{cell}$. The larger value is from the kesterite ferromagnetic phase, whereas the

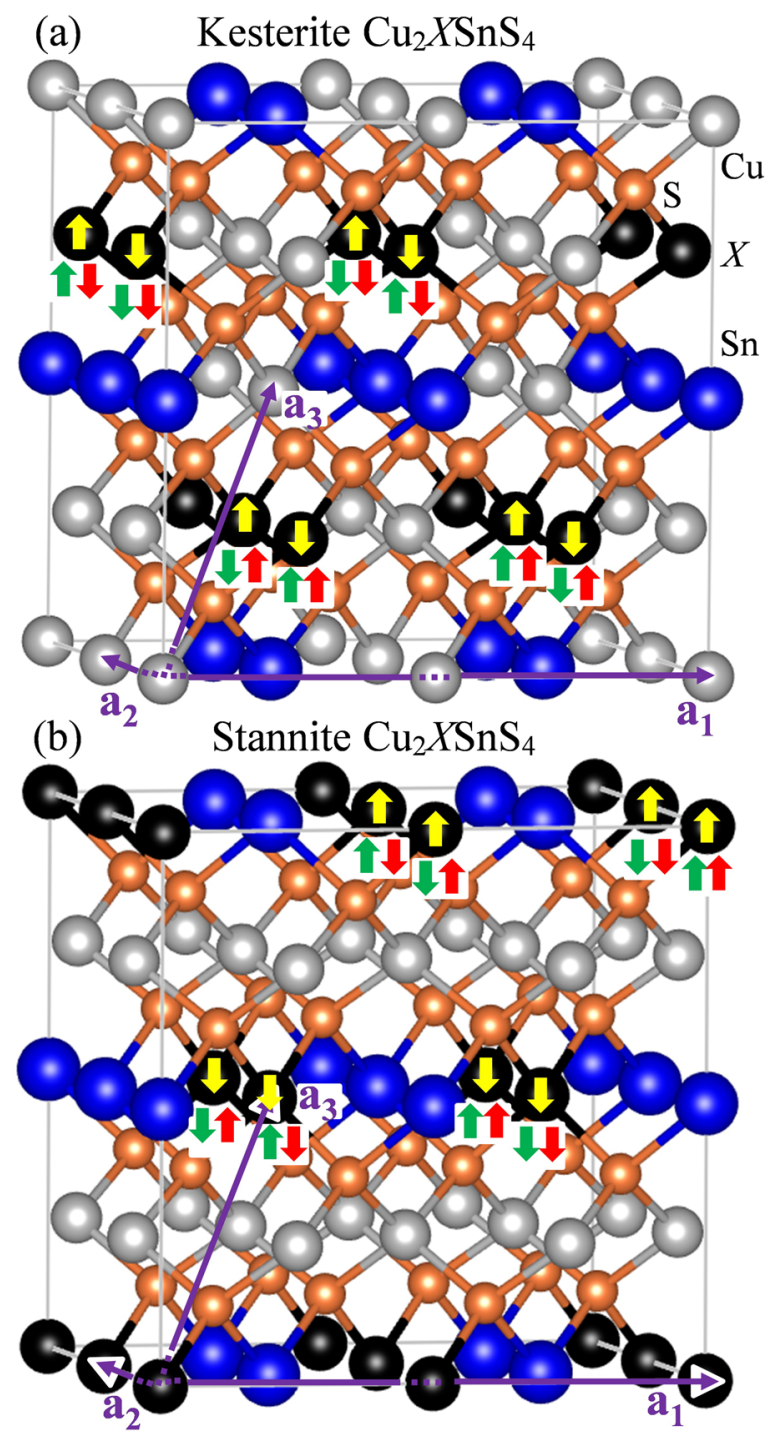

FIG. 1. Crystalline structures of (a) kesterite and (b) stannite $\mathrm{Cu}_{2} X \mathrm{SnS}_{4}$, where the magnetic configurations are indicated by the arrows. The yellow arrows on the $X$-atom site show the most stable antiferromagnetic phase for $X=\mathrm{Mn}, \mathrm{Fe}$, and $\mathrm{Ni}$, while green and red arrows indicate two other antiferromagnetic configurations, respectively, both with higher formation energy. Also, the ferromagnetic phase has higher formation energy. maximal absolute energy differences between the four magnetic configurations are only 24 and $25 \mathrm{meV} / \mathrm{cell}$ for ST and KS, respectively. This may indicate that the paramagnetic phase can exist depending on growth conditions and temperature for $\mathrm{Cu}_{2} \mathrm{MnSnS}_{4}$. For $\mathrm{Cu}_{2} \mathrm{FeSnS}_{4}$, the total energy differences between stable (ST-AFM) and other phases are between 16 and $30 \mathrm{meV}$ per cell; here, the larger value is from the kesterite antiferromagnetic phase. Similarly, for $\mathrm{Cu}_{2} \mathrm{NiSnS}_{4}$, the total energy differences between stable (KSAFM) and other phases are between 95 and $1700 \mathrm{meV} / \mathrm{cell}$; here, the larger value is from the stannite antiferromagnetic phase. The large energy difference demonstrates that the compound has a strong magnetic phase that governs its crystalline structure.

The energy with respect to the formation energy of chemical decomposition, i.e., $\mathrm{Cu}_{2} X \mathrm{SnS}_{4} \rightarrow[2(\mathrm{CuS})+X \mathrm{~S}+\mathrm{SnS}]$, $\left[\mathrm{Cu}_{2} \mathrm{~S}+X \mathrm{~S}+\mathrm{SnS}_{2}\right]$, or $\left[\mathrm{Cu}_{2} \mathrm{SnS}_{3}+X \mathrm{~S}\right]$, indicates possibility for being stable as a compound. Here, $\mathrm{Cu}_{2} \mathrm{MnSnS}_{4}$ and $\mathrm{Cu}_{2} \mathrm{FeSnS}_{4}$ are clearly stable chalcopyrites. $\mathrm{Cu}_{2} \mathrm{NiSnS}_{4}$ is also a theoretically stable compound from this analysis although the energy to decompose is smaller, and this is supported by the fact that at least nanoparticles have been synthesized. ${ }^{14,15}$ The tetragonal compounds containing the group-IIA elements are known to be less stable (or unstable). ${ }^{17,18}$ We find a trend that the light $\mathrm{Be}$ or $\mathrm{Mg}$ atom forms a CXTS crystal with lower formation energy compared to its decomposing compounds, while heavier $\mathrm{Ca}$ elements make the crystal unstable. Thereby, $\mathrm{Cu}_{2} \mathrm{BeSnS}_{4}$ and $\mathrm{Cu}_{2} \mathrm{MgSnS}_{4}$ have stable $\mathrm{KS}$ and ST phases, respectively. Although the trigonal phase is preferable for $\mathrm{Cu}_{2} \mathrm{CaSnS}_{4}$, this phase is also unstable with respect to decomposition. However, the $\mathrm{Cu}_{2} \mathrm{BaSnS}_{4}$ compound, with an even heavier group-IIA element, has a stable trigonal phase, ${ }^{33}$ which also our test calculations demonstrate (not presented in this work). For $\mathrm{Cu}_{2} \mathrm{MgSnS}_{4}$ and $\mathrm{Cu}_{2} \mathrm{NiSnS}_{4}$, the choice of exchange-correlation potential can make deviations. We use HSE06; however, with the PBEsol $(+\mathrm{U})$ potential, the formation energies of the compounds are higher than those of chemical decompositions $\left(\left[\mathrm{Cu}_{2} \mathrm{SnS}_{3}+\mathrm{MgS} / \mathrm{NiS}\right]\right)$; thereby, they can be unstable. This probably explains the somewhat disagreeing results in the earlier studies. ${ }^{17,18}$

In Table I, we present the crystal parameters for the most stable tetragonal structure of the CXTS compounds, and only these configurations are henceforth considered in this study (unless specifically stated). As expected, the bond length of the compounds follows the sum of covalent radii of the atoms. For example, the bond length $\delta(\mathrm{Cu}-\mathrm{S})$ is between 2.28 and $2.32 \AA$ in our results, and the covalent radii of $\mathrm{Cu}$ and $\mathrm{S}$ are $\sim 1.32$ and $\sim 1.05 \AA$. This also holds for $\delta(X-S)$ : for example, the calculated bond length $\delta(\mathrm{Mg}-\mathrm{S})$ is $\sim 2.45 \AA$, and the covalent radius of $\mathrm{Mg}$ is $\sim 1.41 \AA$. The lattice ratio $c / a$ is less than 2 for CXTS, which indicates a stronger relaxation with respect to the ideal zinc-blende-like atomic positions. The stronger relaxation is also obvious from the anion positions (see Table I). Experimentally, the lattice constants for $\mathrm{ST} \mathrm{Cu}_{2} \mathrm{MnSnS}_{4}$ at temperature $T=15.2 \mathrm{~K}$ are $a=5.514 \AA$ and $c / a=1.957,{ }^{34}$ and our results $(a=5.473 \AA$ and $c / a=1.960)$ are in good agreement with these.

The electronic structures and the atomic and angularmomentum dependent DOS (PDOS) of CXTS and CZTS are 
TABLE I. The crystalline lattice parameters $a$ and $c / a$ and the bond lengths $\delta\left(\right.$ cation-S) are presented for the most stable tetragonal phase of $\mathrm{Cu}_{2} X \mathrm{SnS}_{4}$ $(X=\mathrm{Be}, \mathrm{Mg}, \mathrm{Ca}, \mathrm{Mn}, \mathrm{Fe}$, and $\mathrm{Ni})$ and $\mathrm{Cu}_{2} \mathrm{ZnSnS}_{4}$. The available experimental lattice parameters (Refs. 34-37) are presented in parentheses.

\begin{tabular}{|c|c|c|c|c|c|c|c|}
\hline & $\begin{array}{c}\mathrm{KS} \\
\mathrm{Cu}_{2} \mathrm{BeSnS}_{4}\end{array}$ & $\begin{array}{c}\mathrm{ST} \\
\mathrm{Cu}_{2} \mathrm{MgSnS}_{4}\end{array}$ & $\begin{array}{c}\mathrm{ST} \\
\mathrm{Cu}_{2} \mathrm{CaSnS}_{4}\end{array}$ & $\begin{array}{c}\text { ST-AFM } \\
\mathrm{Cu}_{2} \mathrm{MnSnS}_{4}\end{array}$ & $\begin{array}{c}\mathrm{ST}-\mathrm{AFM} \\
\mathrm{Cu}_{2} \mathrm{FeSnS}_{4}\end{array}$ & $\begin{array}{c}\mathrm{KS}-\mathrm{AFM} \\
\mathrm{Cu}_{2} \mathrm{NiSnS}_{4}\end{array}$ & $\begin{array}{c}\mathrm{KS} \\
\mathrm{Cu}_{2} \mathrm{ZnSnS}_{4}\end{array}$ \\
\hline$a(\AA)$ & 5.263 & 5.489 & 5.809 & $5.473\left(5.514^{\mathrm{a}}\right)$ & $5.432\left(5.450^{\mathrm{b}}\right)$ & 5.464 & $5.372\left(5.428^{\mathrm{c}}\right)$ \\
\hline$c / a$ & 1.971 & 1.955 & 1.765 & $1.960\left(1.957^{\mathrm{a}}\right)$ & $1.952\left(1.968^{\mathrm{b}}\right)$ & 1.903 & $2.001\left(2.002^{c}\right)$ \\
\hline \multicolumn{8}{|l|}{ S position } \\
\hline$x$ & 0.750 & 0.749 & 0.729 & 0.750 & 0.756 & 0.755 & $0.768\left(0.756^{\mathrm{d}}\right)$ \\
\hline$y$ & 0.778 & 0.749 & 0.730 & 0.750 & 0.756 & 0.768 & $0.759\left(0.757^{d}\right)$ \\
\hline$z$ & 0.862 & 0.862 & 0.852 & 0.863 & 0.866 & 0.867 & $0.870\left(0.872^{\mathrm{d}}\right)$ \\
\hline$\delta(\mathrm{Cu}-\mathrm{S})(\AA)$ & 2.275 & 2.283 & 2.316 & 2.286 & 2.277 & 2.296 & 2.275 \\
\hline$\delta(X-\mathrm{S})(\AA)$ & 2.111 & 2.449 & 2.694 & 2.436 & 2.350 & 2.280 & 2.329 \\
\hline$\delta(\mathrm{Sn}-\mathrm{S})(\AA)$ & 2.430 & 2.436 & 2.422 & 2.430 & 2.427 & 2.450 & 2.443 \\
\hline
\end{tabular}

${ }^{\mathrm{a}}$ Fries et al. ${ }^{34}$

${ }^{\mathrm{b}}$ Bonazzi et al. $^{35}$

${ }^{\mathrm{c}}$ Schorr et al. ${ }^{36}$

${ }^{\mathrm{d}}$ Hall et al. ${ }^{37}$

presented in Fig. $2\left(\mathrm{Cu}_{2} \mathrm{FeSnS}_{4}\right.$ is fairly similar to $\mathrm{Cu}_{2} \mathrm{MnSnS}_{4}$, and the results are therefore presented in the supplementary material). The band-gap energies are $E_{\mathrm{g}}=1.76$, $1.48,1.84,1.40,1.71,1.26$, and $1.29 \mathrm{eV}$ for CXTS (with $X=\mathrm{Be}, \mathrm{Mg}, \mathrm{Ca}, \mathrm{Mn}, \mathrm{Fe}$, and $\mathrm{Ni}$ ) and $\mathrm{CZTS}$, respectively, obtained from the HSE06 calculations. These gap energies are in fairly good agreement with available experimental results for $\mathrm{Cu}_{2} \mathrm{MgSnS}_{4}\left(E_{\mathrm{g}}=1.63 \mathrm{eV}\right), \mathrm{Cu}_{2} \mathrm{MnSnS}_{4}(1.18-1.63 \mathrm{eV})$, $\mathrm{Cu}_{2} \mathrm{FeSnS}_{4}(1.33$ or $1.5 \mathrm{eV}), \mathrm{Cu}_{2} \mathrm{NiSnS}_{4}(1.40 \mathrm{eV})$, and CZTS $(1.45 \mathrm{eV}){ }^{10-12,14,15,38}$
The electronic structures and PDOS of CXTS are qualitatively similar to those of CZTS (Fig. 2). $\mathrm{Cu} d$-like states hybridize with $\mathrm{S} p$-like states in a wide energy range in the valence band (VB) below the VB maximum (VBM). For the conduction band (CB) states, the DOS is comparable for CXTS (except $\mathrm{Cu}_{2} \mathrm{NiSnS}_{4}$ ) and CZTS, at least from the conduction band minimum (CBM) to some $\sim 3 \mathrm{eV}$ up in energy. Here, it is mainly hybridization between the $\mathrm{Sn} s$-like and $\mathrm{S}$ $p$-like states. It is also noticeable that $\mathrm{Ca}$ and $\mathrm{Mn} d$-like states hybridize with $\mathrm{Sn} p$-like states in the energy range above $3 \mathrm{eV}$.

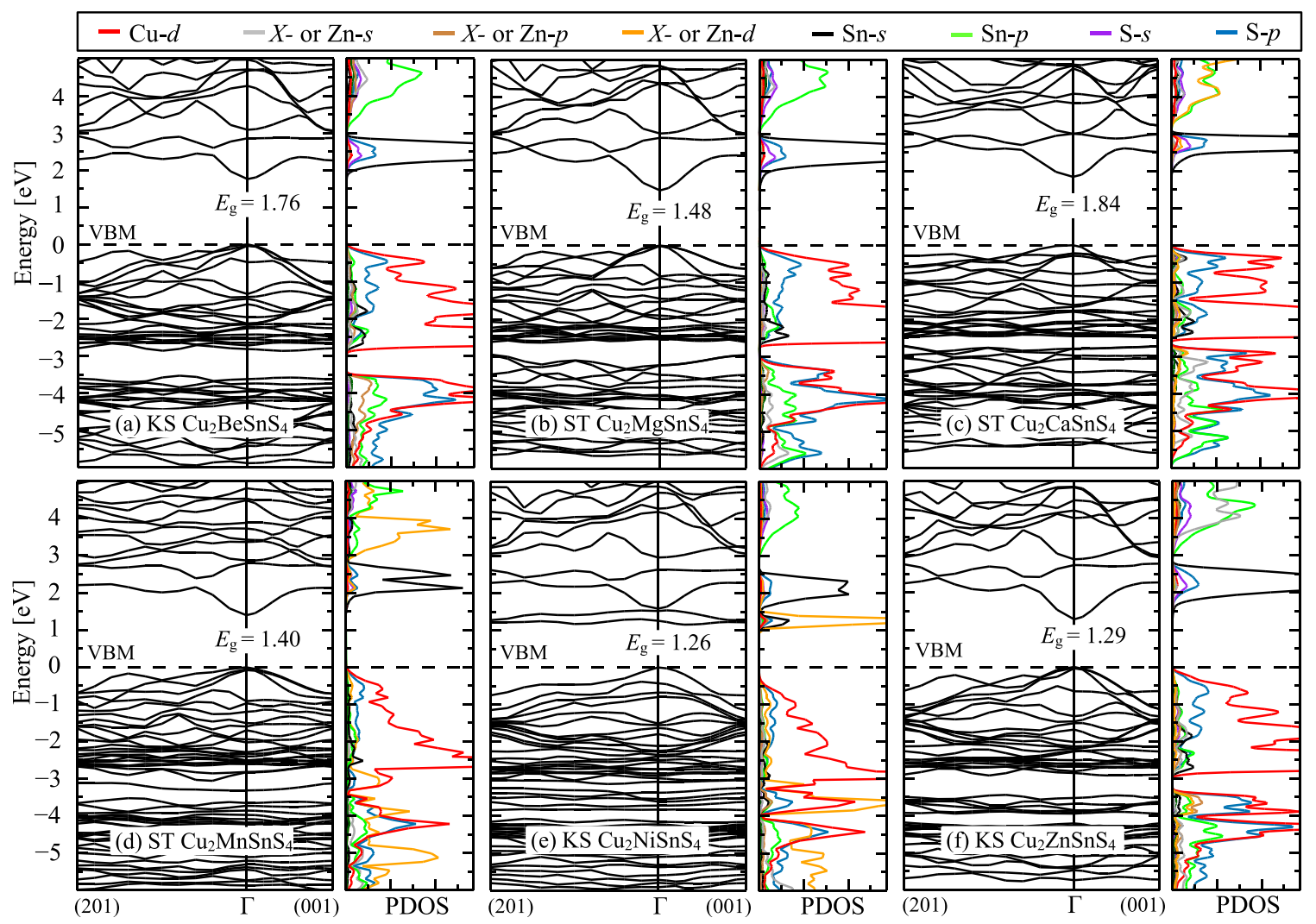

FIG. 2. The electronic band structure and the atom and angular-momentum resolved DOS (PDOS) for the non-magnetic (a) kesterite $\mathrm{Cu}_{2} \mathrm{BeSnS}_{4},(\mathrm{~b}) \mathrm{stannite}$ $\mathrm{Cu}_{2} \mathrm{MgSnS}_{4}$, and (c) stannite $\mathrm{Cu}_{2} \mathrm{CaSnS}_{4}$. The corresponding band structure and PDOS for the magnetic (d) stannite $\mathrm{Cu}_{2} \mathrm{MnSnS}_{4}$ and (e) $\mathrm{kesterite} \mathrm{Cu}_{2} \mathrm{NiSnS}_{4}$; the two spin components are not distinguishable. For comparison, the band structure and DOS of (f) kesterite $\mathrm{Cu}_{2} \mathrm{ZnSnS}_{4}$ are also presented. For better visibility, the PDOS is scaled with $1 /(2 \ell+1)$, where $\ell$ is the angular-momentum quantum number, and presented with a 50 meV Lorentzian broadening. 
$\mathrm{Cu}_{2} \mathrm{NiSnS}_{4}$ is quite different from the others in the aspects of the electronic band structure and PDOS. For instance, in $\mathrm{Cu}_{2} \mathrm{NiSnS}_{4}$, it is mainly the $\mathrm{Ni} d$-like states that hybridize with $\mathrm{Sn} s$-like states between CBM and $\mathrm{CBM}+1 \mathrm{eV}$. As a consequence of this, $\mathrm{Cu}_{2} \mathrm{NiSnS}_{4}$ has an indirect band gap, in contrast to the other considered compound. However, the indirect band-gap energy of $\mathrm{Cu}_{2} \mathrm{NiSnS}_{4}$ is energetically close to the gap energy at the $\Gamma$-point; the difference is only $\sim 10 \mathrm{meV}$. This is a consequence of that the lowest $\mathrm{CB}$ of $\mathrm{Cu}_{2} \mathrm{NiSnS}_{4}$ is very flat, which then in turn can imply advantageously strong photon absorption. However, the disadvantage can be a large effective electron mass.

In Fig. 3, the calculated absorption coefficients $\alpha(\omega)$ of CXTS are presented. A clear onset of absorption occurs near the band-gap energy for all compounds, indicating good dipole-allowed transition probability. Also, all compounds have absorption coefficients similar to CZTS. To better compare $\alpha(\omega)$ for compounds with different band-gap energies, the absorption coefficients in Fig. 3(b) are presented on the energy scale $\left(\hbar \omega-E_{\mathrm{g}}\right)$. One notices that most compounds have a pronounced absorption peak at $\sim 1.3 \mathrm{eV}$, and this peak is at $\sim 1.0 \mathrm{eV}$ for $\mathrm{Cu}_{2} \mathrm{BeSnS}_{4}$ and $\sim 0.8 \mathrm{eV}$ for $\mathrm{Cu}_{2} \mathrm{NiSnS}_{4}$.

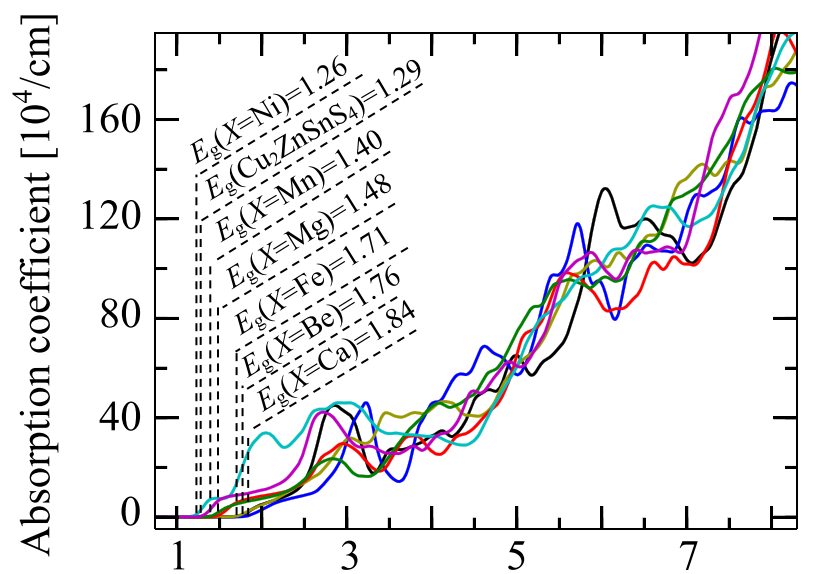

(a)

Energy $\hbar \omega[\mathrm{eV}]$

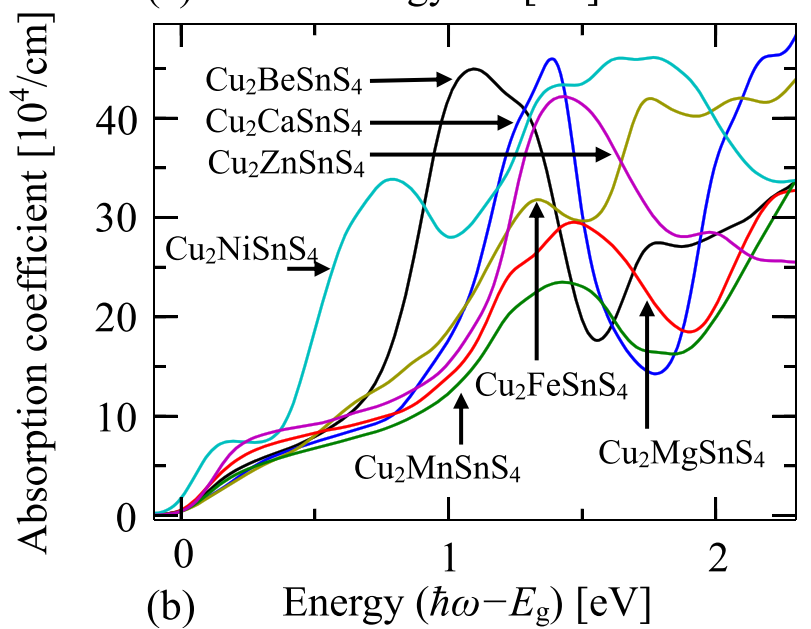

FIG. 3. Absorption coefficients $\alpha(\omega)$ of $\mathrm{CXTS}$ and $\mathrm{Cu}_{2} \mathrm{ZnSnS}_{4}$ from the PBEsol $(+\mathrm{U})$ calculations with band-gap energies $E_{\mathrm{g}}$ adjusted to the HSE06 results: (a) with respect to the photon energy $\hbar \omega$ and (b) a close-up near the absorption onset, where the energy scale is $\left(\hbar \omega-E_{\mathrm{g}}\right)$, to better compare the six compounds. The spectra are presented with an additional $50 \mathrm{meV}$ Lorentzian broadening to the spectrum.
It is therefore obvious that $\mathrm{Cu}_{2} \mathrm{NiSnS}_{4}$ has a much better absorption in the energy region $E_{\mathrm{g}}$ and $E_{\mathrm{g}}+1.0 \mathrm{eV}$ compared to CZTS, and $\mathrm{Cu}_{2} \mathrm{NiSnS}_{4}$ has a good absorption coefficient in a broad energy range due to the very flat Ni $d$-like CBs (cf. Fig. 2). $\mathrm{Cu}_{2} \mathrm{BeSnS}_{4}$ has a higher absorption coefficient than CZTS between $E_{\mathrm{g}}+0.6 \mathrm{eV}$ and $E_{\mathrm{g}}+1.2 \mathrm{eV}$, while $\mathrm{Cu}_{2} \mathrm{MgSnS}_{4}$, $\mathrm{Cu}_{2} \mathrm{MnSnS}_{4}$, and $\mathrm{Cu}_{2} \mathrm{FeSnS}_{4}$ have similar absorption to CZTS from $E_{\mathrm{g}}$ to about $E_{\mathrm{g}}+1 \mathrm{eV}$.

It is worth noticing that, in the calculations for absorption coefficients, a rather dense $\mathbf{k}$-mesh is utilized in the calculations in order to generate a more detailed shape of the absorption spectra near $E_{\mathrm{g}} .{ }^{21}$ Furthermore, based on earlier studies, ${ }^{8,39}$ we expect that the corresponding Se-based compounds (i.e., CXTSe) shall have similar electronic and optical properties to their S-based counterparts but that their corresponding band-gap energies are $\sim 0.5 \mathrm{eV}$ smaller due to the heavier anion atom.

\section{B. Native defects}

To analyze the impact of native defect pairs that contain $\mathrm{Cu}$ vacancies and/or anti-sites, we model and perform calculations of defects in supercells with 64 atoms. One issue regarding the CZTS material is that $\mathrm{Cu}-\mathrm{Zn}$ disorder introduces a band-gap fluctuation. ${ }^{4}$ Therefore, it is of interest not only to calculate how especially ASPs affect the band-gap energies with ASPs but also to calculate the defect formation energy of the compounds in order to suggest if it is possible to reduce the disorder by doping, alloying, or in some other ways. The formation energy of the defect is defined by $\Delta H(D)$ $=E_{\mathrm{tot}}(\mathrm{CXTS}: D)-E_{\mathrm{tot}}(\mathrm{CXTS})+\Sigma_{\alpha} n_{\alpha \cdot} \mu_{\alpha}$. Here, $E_{\mathrm{tot}}(\mathrm{CXTS}: D)$ and $E_{\mathrm{tot}}(\mathrm{CXTS})$ are the total energies for CXTS with and without defect $D$, respectively, and $n_{\alpha}=-1(+1)$ when one atom $\alpha$ is added (removed). The chemical potential is expressed as $\mu_{\alpha}=\mu_{\alpha, \text { sol }}+\Delta \mu_{\alpha}$, where $\mu_{\alpha, \text { sol }}$ is the total energy per atom of the solid compound for element $\alpha^{40} \Delta \mu_{\alpha}$ can vary depending on the external condition, and for simplicity, we set $\Delta \mu_{\alpha}=0$ ( $\alpha$-rich conditions) since the focus is on ASPs in this study with $n_{\alpha}=0$. The binding energy $E_{\mathrm{b}}(D)$ for the complex $D=\left(D_{1}+D_{2}\right)$ containing the two defects $D_{1}$ and $D_{2}$ is calculated as $E_{\mathrm{b}}(D)=\left[E_{\mathrm{tot}}(\mathrm{CXTS}: D)+E_{\mathrm{tot}}(\mathrm{CXTS})\right]-\left[E_{\mathrm{tot}}(\mathrm{CXTS}\right.$ : $\left.\left.D_{1}\right)+E_{\text {tot }}\left(\mathrm{CXTS:} D_{2}\right)\right]$.

The calculated $\Delta H(D)$ and $E_{\mathrm{b}}(D)$ of the native, neutral complexes $\left(\mathrm{V}_{\mathrm{Cu}}+X_{\mathrm{Cu}}\right)$ and $\left(\mathrm{Cu}_{X}+X_{\mathrm{Cu}}\right)$ in CXTS are presented in Table II; native single defects of CZTS are also shown for comparison. In Fig. 4, we compare the total DOS of CXTS with $\mathrm{V}_{\mathrm{Cu}}, \mathrm{Cu}_{X}, X_{\mathrm{Cu}}$, and $\left(\mathrm{Cu}_{X}+X_{\mathrm{Cu}}\right)$ defects with the corresponding DOS of the defect-free compound. First, and without considering the $\mathrm{Cu}_{2} \mathrm{FeSnS}_{4}$ and $\mathrm{Cu}_{2} \mathrm{NiSnS}_{4}$ compounds, the single defects $\mathrm{V}_{\mathrm{Cu}}$ and $X_{\mathrm{Cu}}$ overall have a moderate effect on the electronic structure. For all the compounds, the $\mathrm{V}_{\mathrm{Cu}}^{-}$and $\mathrm{Cu}_{X}^{-}$defects induce rather shallow acceptor states at the VBM, and thus, the Fermi level $E_{\mathrm{F}}$ is below VBM. $\mathrm{V}_{\mathrm{Cu}}^{-}$ is a very delocalized acceptor that has a minor effect on the VB states and acts almost as a hole carrier doping. However, the smaller $\mathrm{Cu}-d-\mathrm{S}-p$ repulsion when the copper-poor $\mathrm{V}_{\mathrm{Cu}}^{-}$ defect is present implies that the band-gap energy is increased (typically by $\Delta E_{\mathrm{g}} \approx 0.1 \mathrm{eV}$ for a defect concentration of

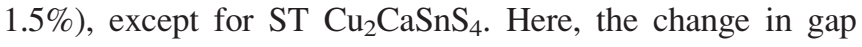


TABLE II. Defect formation energy $\Delta H(D)$ for $\Delta \mu_{\alpha}=0$, binding energy $E_{\mathrm{b}}(D)$ of defect pairs, and the induced shift $\Delta E_{\mathrm{g}}(D)$ of the gap energy for native defects in tetragonal CXTS; all units are in eV. Total magnetic moment $M_{\mathrm{t}}$ units in $\mu_{\mathrm{B}}$ are given for $\mathrm{Cu}_{2} \mathrm{MnSnS}_{4}$ and $\mathrm{Cu}_{2} \mathrm{NiSnS}_{4}$ including the defects, where the local magnetic moment is $\sim 4.4 \mu_{\mathrm{B}}$ for $\mathrm{Mn}\left(4.28 \mu_{\mathrm{B}}\right.$ in Ref. 34$), \sim 3.5 \mu_{\mathrm{B}}$ for $\mathrm{Fe}$, and $\sim 1.5 \mu_{\mathrm{B}}$ for $\mathrm{Ni}$.

\begin{tabular}{|c|c|c|c|c|c|c|c|c|}
\hline Compound & Phase & & $\mathrm{V}_{\mathrm{Cu}}$ & $\mathrm{V}_{X}$ & $X_{\mathrm{Cu}}$ & $\mathrm{Cu}_{X}$ & $\left(\mathrm{~V}_{\mathrm{Cu}}+X_{\mathrm{Cu}}\right)$ & $\left(\mathrm{Cu}_{X}+X_{\mathrm{Cu}}\right)$ \\
\hline \multirow[t]{3}{*}{$\mathrm{Cu}_{2} \mathrm{BeSnS}_{4}$} & KS & $\Delta H$ & 1.50 & 4.14 & 0.19 & 2.33 & -0.28 & 0.58 \\
\hline & & $E_{\mathrm{b}}$ & & & & & -1.97 & -1.94 \\
\hline & & $\Delta E_{\mathrm{g}}$ & 0.00 & -0.12 & -0.22 & -0.26 & 0.07 & -0.30 \\
\hline \multirow[t]{3}{*}{$\mathrm{Cu}_{2} \mathrm{MgSnS}_{4}$} & ST & $\Delta H$ & 1.61 & 4.85 & -0.52 & 2.83 & -1.07 & 0.34 \\
\hline & & $E_{\mathrm{b}}$ & & & & & -2.17 & -1.97 \\
\hline & & $\Delta E_{\mathrm{g}}$ & 0.07 & -0.07 & -0.10 & -0.22 & 0.10 & -0.18 \\
\hline \multirow[t]{3}{*}{$\mathrm{Cu}_{2} \mathrm{CaSnS}_{4}$} & ST & $\Delta H$ & 1.14 & 5.92 & -1.86 & 3.86 & -2.68 & 0.13 \\
\hline & & $E_{\mathrm{b}}$ & & & & & -1.95 & -1.87 \\
\hline & & $\Delta E_{\mathrm{g}}$ & -0.07 & -0.14 & -0.22 & -0.34 & 0.02 & -0.29 \\
\hline \multirow[t]{4}{*}{$\mathrm{Cu}_{2} \mathrm{MnSnS}_{4}$} & ST-AFM & $\Delta H$ & 1.60 & 4.37 & -0.21 & 2.35 & -0.54 & 0.33 \\
\hline & & $E_{\mathrm{b}}$ & & & & & -1.93 & -1.81 \\
\hline & & $\Delta E_{\mathrm{g}}$ & 0.05 & -0.35 & -0.21 & -0.37 & 0.06 & -0.19 \\
\hline & & $M_{\mathrm{t}}$ & 0.1 & 3.0 & 4.6 & 4.0 & 5.0 & 0.0 \\
\hline \multirow[t]{4}{*}{$\mathrm{Cu}_{2} \mathrm{FeSnS}_{4}$} & ST-AFM & $\Delta H$ & 1.64 & 5.94 & -1.67 & 3.81 & -2.01 & 0.35 \\
\hline & & $E_{\mathrm{b}}$ & & & & & -1.98 & -1.80 \\
\hline & & $\Delta E_{\mathrm{g}}$ & -0.02 & -0.83 & -1.08 & -0.26 & 0.01 & -0.17 \\
\hline & & $M_{\mathrm{t}}$ & 0.3 & 2.0 & 2.8 & 2.8 & 3.7 & 0 \\
\hline \multirow[t]{4}{*}{$\mathrm{Cu}_{2} \mathrm{NiSnS}_{4}$} & KS-AFM & $\Delta H$ & 1.57 & 3.09 & -0.22 & 1.08 & 0.60 & 0.36 \\
\hline & & $E_{\mathrm{b}}$ & & & & & -0.75 & -0.49 \\
\hline & & $\Delta E_{\mathrm{g}}$ & -0.07 & -0.18 & 0.00 & -0.22 & -0.15 & -0.53 \\
\hline & & $M_{\mathrm{t}}$ & 0.1 & 2.0 & 1.0 & 2.8 & 2.0 & 0.0 \\
\hline \multirow[t]{3}{*}{$\mathrm{Cu}_{2} \mathrm{ZnSnS}_{4}$} & KS & $\Delta H$ & 1.42 & 3.54 & 0.45 & 1.64 & -0.09 & 0.30 \\
\hline & & $E_{\mathrm{b}}$ & & & & & -1.96 & -1.79 \\
\hline & & $\Delta E_{\mathrm{g}}$ & 0.06 & -0.03 & -0.13 & -0.12 & 0.08 & -0.13 \\
\hline
\end{tabular}

energy refers to changes in the host-like VBM and/or CBM, while the free hole (electron) concentration from the acceptors (donors) implies a larger optical band gap (about $0.2-0.3 \mathrm{eV}$ for a defect concentration of $1.5 \%$ ). Furthermore, the copperrich $\mathrm{Cu}_{X}^{-}$acceptor forms somewhat more localized acceptor states, and these acceptor states shift the VBM energetically upwards. Thereby, the gap energy is decreased $\left(\Delta E_{\mathrm{g}} \approx-0.1\right.$ to $-0.4 \mathrm{eV}$ ), in contrast to $\mathrm{V}_{\mathrm{Cu}}^{-}$. The $X_{\mathrm{Cu}}^{+}$defect induces shallow donor states with the Fermi level in the $\mathrm{CB}$, and the donor shifts the CBM energetically downwards. Thus, similar to the $\mathrm{Cu}_{X}^{-}$acceptor, the $X_{\mathrm{Cu}}^{+}$donor narrows the gap $\left(\Delta E_{\mathrm{g}} \approx 0\right.$ to $-0.2 \mathrm{eV})$ despite that it involves less $\mathrm{Cu}-d-\mathrm{S}-p$ repulsion. The calculated change in the band-gap energy of CZTS is similar to what has been reported previously, ${ }^{4,41}$ where the band-gap energies are reduced by $\sim 0.1 \mathrm{eV}$ for $\mathrm{Zn}_{\mathrm{Cu}}^{+}$and increased by $\sim 0.1 \mathrm{eV}$ for $\mathrm{V}_{\mathrm{Cu}}^{-}$.

From the total energies (Table II), we find that CXTS has similar formation energy of $\mathrm{V}_{\mathrm{Cu}}$ to $\mathrm{CZTS}$ in the $\mathrm{Cu}$-rich limit. This indicates that it is possible to form non-stoichiometric compounds for these CXTS. Moreover, the formation energies of the other single point defects are relatively small (see also Ref. 5), and they can thus easily compensate each other (or other charged defect). Thus, the oppositely charged point defects $\mathrm{V}_{\mathrm{Cu}}^{-}\left(\right.$or $\left.\mathrm{Cu}_{X}^{-}\right)$and $X_{\mathrm{Cu}}^{+}$can be compensated to form neutral complex $\mathrm{Cu}$-poor $\left(\mathrm{V}_{\mathrm{Cu}}^{-}+X_{\mathrm{Cu}}^{+}\right)^{0}$ or $\mathrm{ASP}\left(\mathrm{Cu}_{X}^{-}+X_{\mathrm{Cu}}^{+}\right)^{0}$. The calculated binding energies $E_{\mathrm{b}}(D)$ verify that compensated $\mathrm{Cu}$ vacancy defects and/or APS are favorable. We find that the binding energies of $\left(\mathrm{V}_{\mathrm{Cu}}^{-}+X_{\mathrm{Cu}}^{+}\right)$and $\mathrm{ASP}\left(\mathrm{Cu}_{X}^{-}\right.$ $+X_{\mathrm{Cu}}^{+}$) are as large as $\left|E_{\mathrm{b}}(D)\right|>1 \mathrm{eV}$. This is not so surprising considering that the two constituents are one single acceptor and one single donor, and the energy gain when compensating the donor (or acceptor) is roughly $1 \mathrm{eV}$ when the donor electron (or the acceptor hole) is captured across the band gap with $E_{\mathrm{g}} \approx 1.5 \mathrm{eV}$. Hence, $\left(\mathrm{Cu}_{X}^{-}+X_{\mathrm{Cu}}^{+}\right)$and $\left(\mathrm{V}_{\mathrm{Cu}}^{-}+X_{\mathrm{Cu}}^{+}\right)$form neutral complexes, and one can therefore easily have high concentrations of them.

The formation energy of the ASP does not depend on the external chemical potential of the elements, and we find that $\Delta H(D)$ of $\left(\mathrm{Cu}_{X}^{-}+X_{\mathrm{Cu}}^{+}\right)$is low. Here, $\mathrm{Cu}_{2} \mathrm{MgSnS}_{4}$, $\mathrm{Cu}_{2} \mathrm{MnSnS}_{4}, \mathrm{Cu}_{2} \mathrm{FeSnS}_{4}, \mathrm{Cu}_{2} \mathrm{NiSnS}_{4}$, and CZTS have similar defect formation energies $(\sim 0.3 \mathrm{eV})$. However, $\mathrm{Cu}_{2} \mathrm{BeSnS}_{4}$ has a relatively high defect formation energy $(0.58 \mathrm{eV})$ for its ASP complex. One reason for the larger $\Delta H(D)$ is that the atom size of $\mathrm{Be}$ is much smaller than the sizes of both $\mathrm{Cu}$ and $\mathrm{Sn}$, and the relaxation effect is therefore stronger. For instance, the energy difference of $\Delta H(D)$ between structures with unrelaxed and relaxed $\left(\mathrm{Cu}_{X}^{-}+X_{\mathrm{Cu}}^{+}\right)$defects is $0.60 \mathrm{eV}$ in $\mathrm{Cu}_{2} \mathrm{MgSnS}_{4}$, while $0.96 \mathrm{eV}$ in $\mathrm{Cu}_{2} \mathrm{BeSnS}_{4}$. This extra relaxation effect implies that the formation energy of APS is $\sim 0.3 \mathrm{eV}$ larger in $\mathrm{Cu}_{2} \mathrm{BeSnS}_{4}$ than in similar compounds. This $0.3 \mathrm{eV}$ energy difference may seem to be small, but the defect concentration depends exponentially on defect formation energy: $[N(D)]=N_{\mathrm{s}} g_{\mathrm{q}} \exp \left[-\Delta H(D) /\left(k_{\mathrm{B}} T\right)\right]$, where $N_{\mathrm{s}}$ is the possible defect sites and $g_{\mathrm{q}}$ is the degeneracy factor. $k_{\mathrm{B}} T$ 


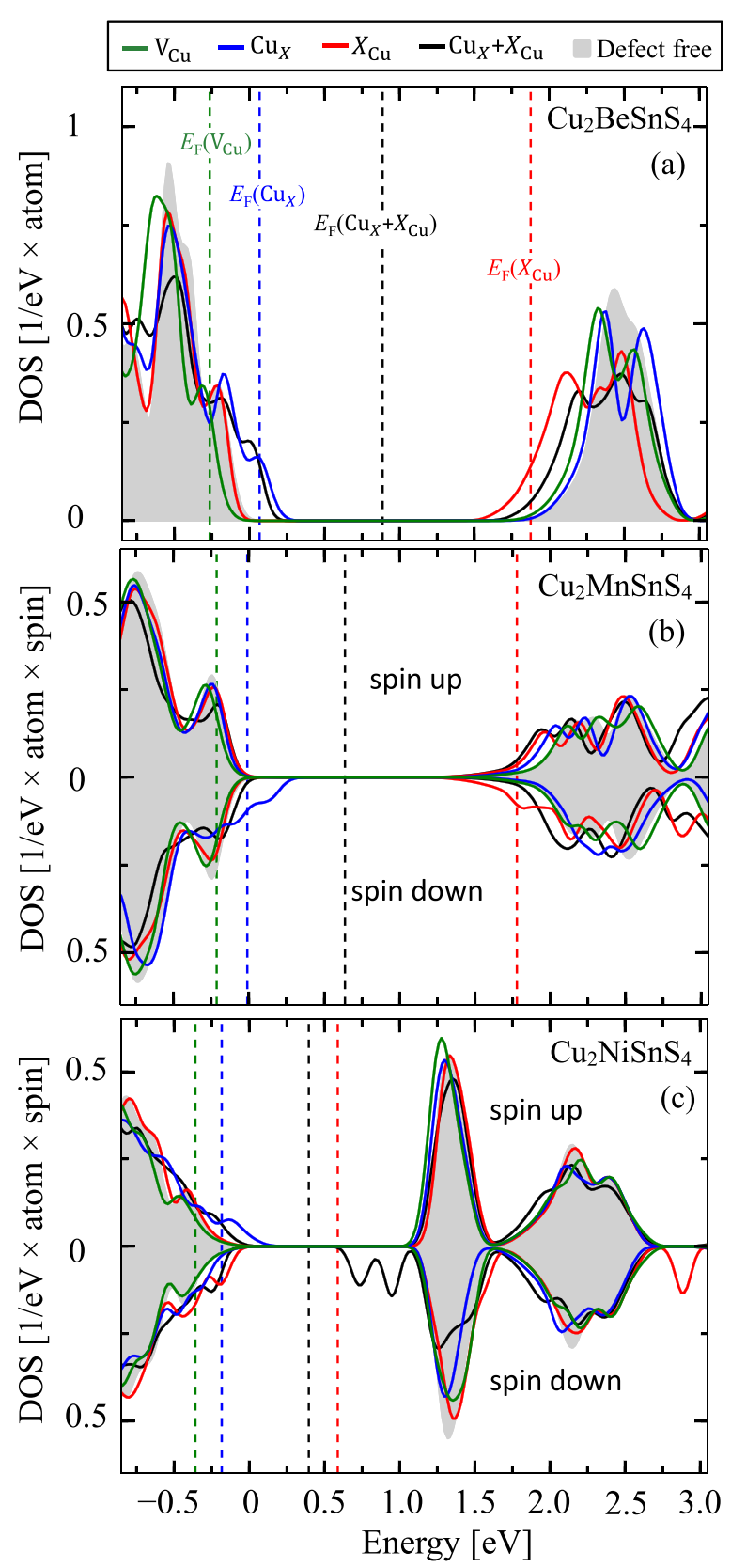

FIG. 4. The total DOS of compounds with the defects $\mathrm{V}_{\mathrm{Cu}}$ (green lines), $\mathrm{Cu}_{X}$ (blue lines), $X_{\mathrm{Cu}}$ (red lines), and $\left(\mathrm{Cu}_{X}+X_{\mathrm{Cu}}\right)$ (black lines), and for comparison, the corresponding DOS for the defect free case (grey area): (a) $\mathrm{Cu}_{2} \mathrm{BeSnS}_{4}$, (b) $\mathrm{Cu}_{2} \mathrm{MnSnS}_{4}$, and (c) $\mathrm{Cu}_{2} \mathrm{NiSnS}_{4}$. The non-magnetic $\mathrm{Cu}_{2} \mathrm{MgSnS}_{4}, \mathrm{Cu}_{2} \mathrm{CaSnS}_{4}$, and $\mathrm{Cu}_{2} \mathrm{ZnSnS}_{4}$ compounds with defects have qualitatively similar DOS to $\mathrm{Cu}_{2} \mathrm{BeSnS}_{4}$, and $\mathrm{Cu}_{2} \mathrm{FeSnS}_{4}$ has similar DOS to $\mathrm{Cu}_{2} \mathrm{MnSnS}_{4}$ apart from having localized in-gap states for $\mathrm{Fe}_{\mathrm{Cu}}$; see supplementary material. The energy refers to VBM of the defect free compound, and the DOS alignment for defects is estimated simply by aligning the semi-core $\mathrm{S} s$-like states. The Fermi levels are indicated with dashed lines, and the DOS are presented with a $50 \mathrm{meV}$ Lorentzian broadening. Spin up and spin down DOS are shown for $\mathrm{Cu}_{2} \mathrm{MnSnS}_{4}$ and $\mathrm{Cu}_{2} \mathrm{NiSnS}_{4}$.

is $\sim 0.03 \mathrm{eV}$ at room temperature, which is only $\sim 1 / 10$ of the considered defect formation energy, and small variations in $\Delta H(D)$ have therefore a large effect on $[N(D)]$. With $N_{\mathrm{s}}$ and $g_{\mathrm{q}}$ fixed, we estimate that the concentration $\left[\left(\mathrm{Cu}_{X}^{-}+X_{\mathrm{Cu}}^{+}\right)\right]$is as much as $\sim 10^{4}$ times lower in $\mathrm{Cu}_{2} \mathrm{BeSnS}_{4}$ than in $\mathrm{Cu}_{2} \mathrm{MgSnS}_{4}, \mathrm{Cu}_{2} \mathrm{MnSnS}_{4}, \mathrm{Cu}_{2} \mathrm{FeSnS}_{4}, \mathrm{Cu}_{2} \mathrm{NiSnS}_{4}$, and CZTS. Since ST $\mathrm{Cu}_{2} \mathrm{CaSnS}_{4}$ has very low ASP formation energy $(0.13 \mathrm{eV})$, the compound is expected to be disordered or actually chemically decomposed. Its trigonal phase has much higher formation energy of its ASP $(1.40 \mathrm{eV})$, and this phase will have a negligible ASP concentration (see Table SI in the supplementary material), but the compound is unfortunately not stable as already discussed.

We also confirm earlier published results ${ }^{19}$ that the ASP in $\mathrm{Cu}_{2} \mathrm{CdSnS}_{4}$ is as easy to be formed as in CZTS despite the larger $\mathrm{Cd}$ atom (see Table SI in the supplementary material). Thus, although sizes of substituting atoms do affect local relaxation of the ions, it is also important to analyze the chemical bonds of the elements to explain the effect on the formation of ASP.

Furthermore, we have found that two ASPs $2\left(\mathrm{Cu}_{X}^{-}+X_{\mathrm{Cu}}^{+}\right)$ show also similar trends in the defect formation energy as a single ASP. In $\mathrm{Cu}_{2} \mathrm{MgSnS}_{4}, \mathrm{Cu}_{2} \mathrm{MnSnS}_{4}$, and $\mathrm{Cu}_{2} \mathrm{NiSnS}_{4}$, the defect formation energy of two complexes (i.e., $2\left(\mathrm{Cu}_{X}^{-}\right.$ $\left.+X_{\mathrm{Cu}}^{+}\right)$) is a little smaller than the sum of the effects due to the presence of two single complexes. Therefore, ASP clusters and/or $\mathrm{Cu}-X$ disorder in are expected to be as strong as for $\mathrm{Cu}-\mathrm{Zn}$ disorder in CZTS. For these compounds, the effect on the electronic structure depends on the concentration of the ASPs. For example, the shift in the gap energies for one ASP $\left(\mathrm{Cu}_{X}^{-}+X_{\mathrm{Cu}}^{+}\right)$is about $\Delta E_{\mathrm{g}} \approx-0.1$ to $-0.2 \mathrm{eV}$ for $\mathrm{Cu}_{2} \mathrm{MgSnS}_{4}$, $\mathrm{Cu}_{2} \mathrm{MnSnS}_{4}, \mathrm{Cu}_{2} \mathrm{FeSnS}_{4}$, and CZTS; one ASP defect implies here $12.5 \%$ disorder. The corresponding energy shift of two ASPs (25\% disorder; not presented in the table) is $\Delta E_{\mathrm{g}} \approx-0.2$ to $-0.4 \mathrm{eV}$ for these four compounds. Since $\left(\mathrm{Cu}_{X}^{-}+X_{\mathrm{Cu}}^{+}\right)$narrows the gap and clustering enhances this effect, non-uniform distributions or concentrations of $\mathrm{Cu}-X$ disorder may imply spatial fluctuations of the band-gap energy in the material. However, the band-gap energy can be stabilized for forming, in addition to clusters of $\left(\mathrm{Cu}_{X}^{-}+X_{\mathrm{Cu}}^{+}\right)$, clusters involving $\mathrm{Cu}-$ poor $\left(\mathrm{V}_{\mathrm{Cu}}^{-}+X_{\mathrm{Cu}}^{+}\right)$defects that increase the gap energy. Here, clustering of neutral $\left(\mathrm{Cu}_{X}^{-}+X_{\mathrm{Cu}}^{+}\right)$with neutral $\left(\mathrm{V}_{\mathrm{Cu}}^{-}+X_{\mathrm{Cu}}^{+}\right)$ can occur due to relaxation effects and preferred octet formation, as modeled by Huang and Persson. ${ }^{41}$ For $\mathrm{Cu}_{2} \mathrm{BeSnS}_{4}$ and $\mathrm{Cu}_{2} \mathrm{CaSnS}_{4}$, on the other hand, the corresponding energy shift due to two ASPs $\left(\Delta E_{\mathrm{g}} \approx-0.4 \mathrm{eV}\right)$ is similar to the shift due to a sole $\operatorname{ASP}\left(\Delta E_{\mathrm{g}} \approx-0.3 \mathrm{eV}\right)$. This may indicate somewhat more localized charge distribution for ASP in these compounds, which is also supported by the stronger relaxation and larger shift $\Delta E_{\mathrm{g}}$ for these compounds. The smaller additive effect is advantageous regarding disorder and may compensate for the larger shift for the low concentration of ASP.

The defect physics of $\mathrm{Cu}_{2} \mathrm{FeSnS}_{4}$ and $\mathrm{Cu}_{2} \mathrm{NiSnS}_{4}$ are somewhat different from that of the compounds discussed above and requires therefore a special discussion. For $\mathrm{Cu}_{2} \mathrm{FeSnS}_{4}$, the ASPs and $\mathrm{Cu}$-poor $\left(\mathrm{V}_{\mathrm{Cu}}^{-}+X_{\mathrm{Cu}}^{+}\right)$defects behave similar to $\mathrm{Cu}_{2} \mathrm{MnSnS}_{4}$, and being neutral, change the band gap energy moderately. However, the point defect $\mathrm{Fe}_{\mathrm{Cu}}$ forms a localized defect level in the middle of the band gap region (see Fig. S2 in the supplementary material). If the point defect is uncompensated, for Fe-rich materials, it can be devastating for device performance. The $\mathrm{Fe}_{\mathrm{Cu}}$ defects need thus to be avoided or to be fully compensated by for instance $\mathrm{V}_{\mathrm{Cu}}^{-}$. Moreover, both $\mathrm{Fe}_{\mathrm{Cu}}$ and $\mathrm{V}_{\mathrm{Fe}}$ narrow the band gap considerably (Table II), and thus, neither Fe-rich nor Fe- 
poor materials are preferable unless these point defects are compensated.

$\mathrm{Cu}_{2} \mathrm{NiSnS}_{4}$ has very good optical properties due to energetically low-lying $\mathrm{Ni} d$-like states at the CBM, which form flat $\mathrm{CB}$. This compound does not have the same problem with point defects as $\mathrm{Cu}_{2} \mathrm{FeSnS}_{4}$; instead these defects are in much sense similar to the other CXTS. However, a striking difference is that $\mathrm{Ni}_{\mathrm{Cu}}$ does not form shallow donor states. Instead, we find that $\mathrm{Ni}_{\mathrm{Cu}}$ forms a magnetic defect and that $E_{\mathrm{F}}$ is inside the gap region of the host $\mathrm{Cu}_{2} \mathrm{NiSnS}_{4}$ (Fig. 4). Since $\mathrm{Ni}_{\mathrm{Cu}}$ is not a shallow donor, the binding energies of the complexes $\left(\mathrm{V}_{\mathrm{Cu}}+\mathrm{Ni}_{\mathrm{Cu}}\right)$ and $\left(\mathrm{Cu}_{\mathrm{Ni}}+\mathrm{Ni}_{\mathrm{Cu}}\right)$ are small: $\left|E_{\mathrm{b}}(D)\right|<0.8 \mathrm{eV}$. However, the defect formation energies of $\mathrm{V}_{\mathrm{Cu}}$ and ASP $\left(\mathrm{Cu}_{\mathrm{Ni}}+\mathrm{Ni}_{\mathrm{Cu}}\right)$ are as small as those for CZTS. Thus, the point defects can be less affected by compensation and thereby more mobile compared to the other compounds. Nevertheless, it will be difficult to avoid disorder from the high concentration of ASP also in $\mathrm{Cu}_{2} \mathrm{NiSnS}_{4}$. Moreover, the ASP forms more localized and magnetic defect states in the gap region. This can be devastating for a PV material, and thus, $\mathrm{Cu}_{2} \mathrm{NiSnS}_{4}$ is perhaps challenging to be utilized as a $\mathrm{PV}$ absorber.

\section{CONCLUSION}

To conclude, employing the HSE06 method, we study the electronic and optical properties of CXTS $(X=\mathrm{Be}, \mathrm{Mg}$, $\mathrm{Ca}, \mathrm{Mn}, \mathrm{Fe}$, and $\mathrm{Ni}$ ) as well as the impact of their native defect pairs. First, the most stable ground-state phases of CXTS are estimated from the calculated total energies of different crystalline and magnetic configurations. We find that $\mathrm{Cu}_{2} \mathrm{MgSnS}_{4}, \mathrm{Cu}_{2} \mathrm{MnSnS}_{4}$, and $\mathrm{Cu}_{2} \mathrm{FeSnS}_{4}$ are stable in the ST phase $D_{2 d}^{11}$, while $\mathrm{Cu}_{2} \mathrm{BeSnS}_{4}$ and $\mathrm{Cu}_{2} \mathrm{NiSnS}_{4}$ compounds favor the KS phase $S_{4}^{2}$ just like CZTS. The total energy difference to the second stable phase is however moderate, at most $\sim 0.25 \mathrm{eV}$ per formula unit. The formation energies of CXTS $(X=\mathrm{Be}, \mathrm{Mg}$, and $\mathrm{Ni})$ are similar to those of CZTS. However, $\mathrm{Cu}_{2} \mathrm{MnSnS}_{4}$ and $\mathrm{Cu}_{2} \mathrm{FeSnS}_{4}$ are clearly stable phases. Thereby, these compounds probably are more stable with high temperature or pressure during synthesis. Considering tetragonal phases, $\mathrm{ST} \mathrm{Cu}_{2} \mathrm{CaSnS}_{4}$ has lower formation energy compared to its $\mathrm{KS}$ phase, but this compound prefers (just like $\mathrm{Cu}_{2} \mathrm{BaSnS}_{4}$ ) the trigonal $C_{3}^{2}$ crystalline structure. However, even with this phase, $\mathrm{Cu}_{2} \mathrm{CaSnS}_{4}$ is not stable with respect to decomposition.

Second, the considered CXTS compounds have suitable band-gap energies $\left(E_{\mathrm{g}}=1.2-1.9 \mathrm{eV}\right)$ for photovoltaic applications; here, Se-S alloying is expected to yield up to $0.5 \mathrm{eV}$ smaller $E_{\mathrm{g}}$, and thus, alloying can be applied for compounds with too large gap. Also, the absorption coefficients are very good: $\alpha(\omega) \approx(10-40) \times 10^{4} \mathrm{~cm}^{-1}$ at $E_{\mathrm{g}}+1.0 \mathrm{eV}$. Here, $\mathrm{Cu}_{2} \mathrm{NiSnS}_{4}$ presents the best absorption for low-energy photons. However, for $\mathrm{Cu}_{2} \mathrm{NiSnS}_{4}$, the ASP yields localized defect states, and this compound may therefore not be suitable for PV applications. In addition, $\mathrm{Ni}_{\mathrm{Cu}}$ does not act as a single donor like corresponding $X_{\mathrm{Cu}}$ in the other compounds.

Third, in all compounds (here, considering the trigonal structure of $\mathrm{Cu}_{2} \mathrm{CaSnS}_{4}$ ), a significant band-gap narrowing occurs in the presence of $\mathrm{Cu}_{X}$ or $X_{\mathrm{Cu}}$ and consequently also with their defect pair $\left(\mathrm{Cu}_{X}+X_{\mathrm{Cu}}\right)$. For the anti-site pair, the shift is $\Delta E_{\mathrm{g}} \approx-0.1$ to $-0.2 \mathrm{eV}$ with $12.5 \%$ disorder concentration for $\mathrm{Cu}_{2} \mathrm{MgSnS}_{4}, \mathrm{Cu}_{2} \mathrm{MnSnS}_{4}, \mathrm{Cu}_{2} \mathrm{FeSnS}_{4}$, and $\mathrm{Cu}_{2} \mathrm{ZnSnS}_{4}$, whereas it is twice as a large impact $\left(\Delta E_{\mathrm{g}} \approx-0.2\right.$ to $-0.4 \mathrm{eV}$ ) for $\mathrm{Cu}_{2} \mathrm{BeSnS}_{4}$ and trigonal $\mathrm{Cu}_{2} \mathrm{CaSnS}_{4}$. As expected from the $\mathrm{Cu}-d-\mathrm{S}-p$ repulsion of the VB states, the gap energies are increased by the presence of not only $\mathrm{V}_{\mathrm{Cu}}$ but also $\left(\mathrm{V}_{\mathrm{Cu}}+X_{\mathrm{Cu}}\right)$, which indicates that $\mathrm{V}_{\mathrm{Cu}}$ rules over $X_{\mathrm{Cu}}$; the exception is for $\mathrm{Cu}_{2} \mathrm{FeSnS}_{4}$ and $\mathrm{Cu}_{2} \mathrm{NiSnS}_{4}$ with less trivial $X_{\mathrm{Cu}}$ defects.

Fourth, due to the low formation energy of $\left(\mathrm{Cu}_{X}+X_{\mathrm{Cu}}\right)$, we conclude that it is difficult to avoid disordering from the high concentration of these ASPs in most of the CXTS compounds. However, in $\mathrm{Cu}_{2} \mathrm{BeSnS}_{4}$, the formation energy is higher, and we expect $\sim 10^{4}$ times lower concentration of the disordering at room and operating temperatures than for the other compounds. We compare the trigonal Ca-compound with the other tetragonal compounds because there can be structural effects. Moreover, the Ca-compound is not stable. Our focus is on tetragonal structures. The lower concentration in $\mathrm{Cu}_{2} \mathrm{BeSnS}_{4}$ is explained partly by the larger relaxation effects in these two compounds as the difference between $\mathrm{Cu}$ and the two anti-site atoms of Be is more obvious than those between $\mathrm{Mg}$, Mn, Fe, or Zn. However, relaxation effects due to sizes of cations cannot fully describe the formation energies of substitutes, and the properties of the chemical elements are also important to be considered. The disadvantage of ASP with different atom sizes is that the stronger relaxation influences the electronic structure, and the band-gap narrowing $\left|\Delta E_{\mathrm{g}}\right|$ is larger for a given defect concentration for $\mathrm{Cu}_{2} \mathrm{BeSnS}_{4}$. Moreover, $\mathrm{Be}$ is a toxic element and difficult to handle in synthesis processes, which makes it less favorable. $\mathrm{Cu}_{2} \mathrm{CaSnS}_{4}$, on the other hand, is not stable in the tetragonal phase nor in its trigonal phase. The stability of $\mathrm{Cu}_{2} \mathrm{MgSnS}_{4}$ is contradictorily predicted using DFT. ${ }^{17,18}$ One may speculate the impact of ASP for other CXTS compounds and also related chalcopyrite materials, but further studies and development of the compounds and their native point defects and ASP are required. Moreover, we expect that corresponding Se-based compounds $\mathrm{Cu}_{2} X \mathrm{SnSe}_{4}$ are expected to have similar defect properties as the S-based compounds $\mathrm{Cu}_{2} \mathrm{XSnS}_{4}$, and also, this has to be investigated.

\section{SUPPLEMENTARY MATERIAL}

See supplementary material for the complementary band structure and DOS of $\mathrm{Cu}_{2} \mathrm{FeSnS}_{4}$ in Fig. S1, the total DOS of compounds with defects $\mathrm{V}_{\mathrm{Cu}}, \mathrm{Cu}_{X}, X_{\mathrm{Cu}}$, and $\left(\mathrm{Cu}_{X}+X_{\mathrm{Cu}}\right)$, as well as the corresponding DOS for the defect free case: (a) $\mathrm{Cu}_{2} \mathrm{MgSnS}_{4}$, (b) $\mathrm{Cu}_{2} \mathrm{CaSnS}_{4}$, (c) $\mathrm{Cu}_{2} \mathrm{FeSnS}_{4}$, and (d) $\mathrm{Cu}_{2} \mathrm{ZnSnS}_{4}$ in Fig. S2, and complementary defect energies of the trigonal phase of $\mathrm{Cu}_{2} \mathrm{CaSnS}_{4}$ and the tetragonal ST phases of $\mathrm{Cu}_{2} \mathrm{CdSnS}_{4}$ in Table SI.

\section{ACKNOWLEDGMENTS}

We thank the Research Council of Norway (project 243642) and the Swedish Foundation for Strategic Research for financial support. We acknowledge access to HPC resources Abel at UiO in Norway operated by USIT and 
allocation provided through NOTUR, Beskow at $\mathrm{KTH}$ operated by PDC and Triolith at LiU operated by NSC, both in Sweden, and allocation was provided through SNIC. We also acknowledge PRACE for awarding access to resource MareNostrum based in Spain at BSC-CNS and access to the DECI resource Archer based in the UK Edinburgh with support from the PRACE aisbl.

${ }^{1}$ W. Wang, M. T. Winkler, O. Gunawan, T. Gokmen, T. K. Todorov, Y. Zhu, and D. B. Mitzi, Adv. Energy Mater. 4, 1301465 (2014).

${ }^{2}$ Copper Zinc Tin Sulphide-Based Thin Film Solar Cells, edited by K. Ito (John Wiley \& Sons, Chichester, 2015).

${ }^{3}$ S. Schorr, Sol. Energy Mater. Sol. Cells 95, 1482 (2011).

${ }^{4}$ J. J. S. Scragg, J. K. Larsen, M. Kumar, C. Persson, J. Sendler, S. Siebentritt, and C. Platzer-Björkman, Phys. Status Solidi B 253, 247 (2016).

${ }^{5}$ S. Chen, J.-H. Yang, X. G. Gong, A. Walsh, and S.-H. Wei, Phys. Rev. B 81, 245204 (2010).

${ }^{6}$ A. Nagoya, R. Asahi, R. Wahl, and G. Kresse, Phys. Rev. B 81, 113202 (2010).

${ }^{7}$ S. Siebentritt and S. Schorr, Prog. Photovoltaics 20, 512 (2012).

${ }^{8}$ M. Kumar, H. Zhao, and C. Persson, Thin Solid Films 535, 318 (2013).

${ }^{9}$ S. Bourdais, C. Chon, B. Delatouche, A. Jacob, G. Larramona, C. Moisan, A. Lafond, F. Donatini, G. Rey, S. Siebentritt, A. Walsh, and G. Dennler, Adv. Energy Mater. 6, 1502276 (2016).

${ }^{10}$ L. Chen, H. Deng, J. Tao, H. Cao, L. Huang, L. Sun, P. Yang, and J. Chu, RSC Adv. 5, 84295 (2015).

${ }^{11}$ L. Li, X. Liu, J. Huang, M. Cao, S. Chen, Y. Shen, and L. Wang, Mater. Chem. Phys. 133, 688 (2012).

${ }^{12}$ X. Zhang, N. Bao, K. Ramasamy, Y. H. A. Wang, Y. Wang, B. Lin, and A. Gupta, Chem. Commun. 48, 4956 (2012).

${ }^{13}$ B. Murali, M. Madhuri, and S. B. Krupanidhi, Cryst. Growth Des. 14, 3685 (2014).

${ }^{14}$ T.-X. Wang, Y.-G. Li, H.-R. Liu, H. Li, and S.-X. Chen, Mater. Lett. 124, 148 (2014).

${ }^{15}$ A. Kamble, K. Mokurala, A. Gupta, S. Mallick, and P. Bhargava, Mater. Lett. 137, 440 (2014).

${ }^{16}$ M. Wei, Q. Du, R. Wang, G. Jiang, W. Liu, and C. Zhu, Chem. Lett. 43, 1149 (2014).

${ }^{17}$ C. Wang, S. Chen, J. H. Yang, L. Lang, H. J. Xiang, X. G. Gong, A. Walsh, and S.-H. Wei, Chem. Mater. 26, 3411 (2014).
${ }^{18}$ G. Zhong, K. Tse, Y. Zhang, X. Li, L. Huang, C. Yang, J. Zhu, Z. Zeng, Z. Zhang, and X. Xiao, Thin Solid Films 603, 224 (2016).

${ }^{19}$ B. G. Mendis, M. D. Shannon, M. C. J. Goodman, J. D. Major, A. A. Taylor, D. P. Halliday, and K. Durose, J. Phys. Conf. Ser. 471, 012014 (2013).

${ }^{20}$ Z.-K. Yuan, S. Chen, H. Xiang, X.-G. Gong, A. Walsh, J.-S. Park, I. Repins, and S.-H. Wei, Adv. Funct. Mater. 25, 6733 (2015).

${ }^{21}$ A. Crovetto, R. Chen, R. B. Ettlinger, A. C. Cazzaniga, J. Schou, C. Persson, and O. Hansen, Sol. Energy Mater. Sol. Cells 154, 121 (2016).

${ }^{22}$ C. H. Henry, J. Appl. Phys. 51, 4494 (1980).

${ }^{23}$ W. Shockley and H. J. Queisser, J. Appl. Phys. 32, 510 (1961).

${ }^{24}$ G. Kresse and D. Joubert, Phys. Rev. B 59, 1758 (1999).

${ }^{25}$ G. Kresse and J. Furthmüller, Phys. Rev. B 54, 11169 (1996).

${ }^{26}$ J. P. Perdew, K. Burke, and M. Ernzerhof, Phys. Rev. Lett. 77, 3865 (1996).

${ }^{27}$ J. P. Perdew, A. Ruzsinszky, G. I. Csonka, O. A. Vydrov, G. E. Scuseria, L. A. Constantin, X. Zhou, and K. Burke, Phys. Rev. Lett. 100, 136406 (2008).

${ }^{28}$ V. I. Anisimov, J. Zaanen, and O. K. Andersen, Phys. Rev. B 44, 943 (1991).

${ }^{29}$ C. E. Cava, L. S. Roman, and C. Persson, Phys. Rev. B 88, 045136 (2013).

${ }^{30}$ W. Setyawan, R. M. Gaume, S. Lam, R. S. Feigelson, and S. Curtarolo, ACS Comb. Sci. 13, 382 (2011).

${ }^{31}$ C. Persson, C. Dong, L. Vayssieres, A. Augustsson, T. Schmitt, M. Mattesini, R. Ahuja, J. Nordgren, C. Chang, A. Ferreira da Silva, and J.-H. Guo, Microelectron. J. 37, 686 (2006).

${ }^{32}$ J. Heyd, G. E. Scuseria, and M. Ernzerhof, J. Chem. Phys. 118, 8207 (2003).

${ }^{33}$ D. Shin, B. Saparov, T. Zhu, W. P. Huhn, V. Blum, and D. B. Mitzi, Chem. Mater. 28, 4771 (2016).

${ }^{34}$ T. Fries, Y. Shapira, F. Palacio, M. C. Morón, G. J. McIntyre, R. Kershaw, A. Wold, and E. J. McNiff, Phys. Rev. B 56, 5424 (1997).

${ }^{35}$ P. Bonazzi, L. Bindi, G. P. Bernardini, and S. Menchetti, Can. Miner. 41, 639 (2003).

${ }^{36}$ S. Schorr, H. J. Hoebler, and M. Tovar, Eur. J. Miner. 19, 65 (2007).

${ }^{37}$ S. R. Hall, J. T. Szymanski, and J. M. Stewart, Can. Mineral. 16, 131 (1978).

${ }^{38}$ P. M. P. Salomé, J. Malaquias, P. A. Fernandes, M. S. Ferreira, A. F. da Cunha, J. P. Leitão, J. C. González, and F. M. Matinaga, Sol. Energy Mater. Sol. Cells 101, 147 (2012).

${ }^{39}$ H. Zhao and C. Persson, Thin Solid Films 519, 7508 (2011).

${ }^{40}$ C. Persson, S. Lany, Y.-J. Zhao, and A. Zunger, Phys. Rev. B 72, 035211 (2005).

${ }^{41}$ D. Huang and C. Persson, Thin Solid Films 535, 265 (2013). 